\title{
Neuroprotective Effect of Oxyresveratrol from Smilacis Chinae Rhizome on Amyloid $\beta$ Protein (25-35)-Induced Neurotoxicity in Cultured Rat Cortical Neurons
}

\author{
Ju Yeon Ban, ${ }^{a, \#}$ So-Young Jeon,,${ }^{b, \#}$ Thi Thuy Ha NGuYen, ${ }^{a}$ KiHwan BAE, ${ }^{c}$ Kyung-Sik Song, ${ }^{b}$ and \\ Yeon Hee SEONG ${ }^{*, a}$ \\ ${ }^{a}$ College of Veterinary Medicine and Research Institute of Herbal Medicine, Chungbuk National University; Cheongju, \\ Chungbuk, 361-763, South Korea: ${ }^{b}$ College of Agriculture and Life-Sciences, Kyungpook National University; Daegu, \\ 702-701, South Korea: and ${ }^{c}$ College of Pharmacy, Chungnam National University; Taejon, 305-764, South Korea. \\ Received August 10, 2006; accepted September 11, 2006
}

We previously reported that Smilacis chinae rhizome inhibits amyloid $\beta$ protein $(25-35)(\mathbf{A} \beta$ (25-35))-induced neurotoxicity in cultured rat cortical neurons. The present study evaluated the neuroprotective effect of oxyresveratrol isolated from Smilacis chinae rhizome against $A \beta(25-35)$-induced neurotoxicity on cultured rat cortical neurons. Oxyresveratrol over the concentration range of $1-10 \mu_{\mathrm{M}}$ significantly inhibited $10 \mu_{\mathrm{M}} \mathrm{A} \beta(25-$ 35)-induced neuronal cell death, which was measured by a 3-[4,5-dimethylthiazol-2-yl]-2,5-diphenyl-tetrazolium bromide (MTT) assay and Hoechst 33342 staining. Oxyresveratrol $\left(10 \mu_{\mathrm{M}}\right)$ inhibited $10 \mu_{\mathrm{M} \mathrm{A}} \boldsymbol{\beta}(25-35)$-induced elevation of cytosolic calcium concentration $\left(\left[\mathrm{Ca}^{2+}\right]_{c}\right)$, which was measured by a fluorescent dye, Fluo-4 AM. Oxyresveratrol $(1,10 \mu \mathrm{M})$ also inhibited glutamate release into medium and reactive oxygen species (ROS) generation induced by $10 \mu \mathrm{m} A \beta(25-35)$. These results suggest that oxyresveratrol prevents $\mathrm{A} \beta$ (25-35)-induced neuronal cell damage by interfering with the increase of $\left[\mathrm{Ca}^{2+}\right]_{c}$, and then by inhibiting glutamate release and ROS generation. Furthermore, these effects of oxyresveratrol may be associated with the neuroprotective effect of Smilacis chinae rhizome.

Key words oxyresveratrol; Smilax chinae rhizome; $\beta$-amyloid protein; neurotoxicity; cortical neuron; neuroprotection

Alzheimer's disease (AD) is characterized by neuronal loss and extracellular senile plaque, whose major constituent is $\beta$ amyloid protein $(\mathrm{A} \beta)$, a $39-43$ amino acid peptide derived from amyloid precursor protein. ${ }^{1)}$ Both in vitro and in vivo studies have reported the toxic effects of $\mathrm{A} \beta$ or $\mathrm{A} \beta$ peptide fragments suggesting an important role for $A \beta$ in the pathogenesis of $\mathrm{AD}^{2,3)}$ In cultures, $\mathrm{A} \beta$ can directly induce neuronal cell death and render neurons vulnerable to excitotoxicity and oxidative insults. ${ }^{4-6)}$ The mechanisms underlying A $\beta$-neurotoxicity are complex but may involve $N$-methyl-Daspartate (NMDA) receptor, a glutamate receptor subtype, modulation induced by glutamate release, sustained elevations of intracellular $\mathrm{Ca}^{2+}$ concentration $\left(\left[\mathrm{Ca}^{2+}\right]_{\mathrm{i}}\right)$, and oxidative stresses. $^{7-10)}$

Hydroxystilbenes, naturally occurring polyphenolic compounds, have attracted significant attention because of their powerful free radical scavenging properties. ${ }^{11-13)}$ Resveratrol (trans-3',4,5'-trihydroxystilbene), a representative of this group, has been widely investigated for its neuroprotective effects in various brain pathological models including experimental cerebral ischemia. ${ }^{14,15)}$ Resveratrol also has been reported to exert a potential neuroprotective property against $\mathrm{A} \beta$-induced toxicity in various neuronal cultures, which is mainly attributable to its antioxidant effect, suggesting its therapeutic potential in AD. ${ }^{16-19)}$ The likewise naturally occurring analogue oxyresveratrol (trans-2,3',4,5' -tetrahydroxystilbene) is also well known as a strong scavenger of free radicals. Lorenz et al. demonstrated that oxyresveratrol effectively scavenges hydrogen peroxide $\left(\mathrm{H}_{2} \mathrm{O}_{2}\right)$, nitric oxide (NO), and the artificial free radical 2,2-diphenyl-1-picrylhydrazyl (DPPH) in microglial cells. ${ }^{20)}$ It was demonstrated that oxyresveratrol inhibited neuronal apoptotic death in cerebral ischemia model. ${ }^{21)}$ Moreover, it has been reported that oxyresveratrol may exert direct protective effects in the brain by crossing the BBB and may prove an excellent complementary drug for the treatment of neurodegenerative disorders that causally involve oxidative/nitrosative stress, especially in stroke. ${ }^{21,22)}$ However, it remains undemonstrated whether oxyresveratrol exerts neuroprotection against $\mathrm{A} \beta$-induced neuronal damage. In a recent study, we reported that methanol extract of Smilacis chinae rhizome protected $\mathrm{A} \beta$ (25-35)-induced neuronal cell damage in cultured rat cortical neurons. ${ }^{23)}$ We isolated various active components including oxyresveratrol, 3,4-dihydroxybenzoic acid, catechin and epicatechin, to which Smilacis chinae rhizome-induced neuroprotection might be attributable. The aim of the present study was to investigate the neutoprotective effect of oxyresveratrol derived from Smilacis chinae rhizome against A $\beta$ (25-35)induced neuronal death, and the underlying mechanism in primary cultured rat cortical neurons.

\section{MATERIALS AND METHODS}

Plant Material, Extraction, Isolation and Instrumental Analysis Smilacis chinae rhizome was purchased at an herbal medicine market in Daegu, Korea and identified by Dr. Jong-Hwan Kwak at Sungkyunkwan University, Suwon, Korea. A voucher specimen (No. SC-0401) has been deposited at The Innovative Research Laboratory of Natural Products Medicine, Kyungpook National University, Daegu, Korea. The dried Smilacis chinae rhizome $(1.8 \mathrm{~kg})$ was refluxed in $\mathrm{MeOH}(2000 \mathrm{ml} \times 3)$ and its extract was evaporated to dryness. The $\mathrm{MeOH}$ extract $(100.0 \mathrm{~g})$ was suspended in water and the suspension was consecutively partitioned with methylene chloride $\left(\mathrm{CH}_{2} \mathrm{Cl}_{2}, 700 \mathrm{ml} \times 3\right)$ and ethyl acetate (EtOAc, $700 \mathrm{ml} \times 3$ ). The EtOAc layer showed high 


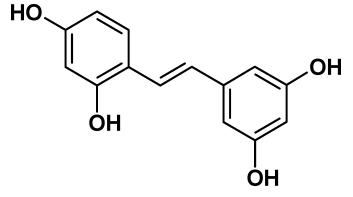

Fig. 1. The Chemical Structure of Oxyresveratrol

inhibitory activity on the $\mathrm{A} \beta$ (25-35)-induced neuronal cell death (unpublished data). The EtOAc soluble fraction $(6.9 \mathrm{~g})$ was chromatographed on a Sephadex LH-20 column $(4.0 \times 68.0 \mathrm{~cm}$, stepwise gradient of 50 to $100 \% \mathrm{MeOH})$ to yield nineteen fractions (Fr. 1-19). The Fr. 10 was rechromatographed through a silica gel column $(1.4 \times 40 \mathrm{~cm}$, $\left.\mathrm{CH}_{2} \mathrm{Cl}_{2}-\mathrm{MeOH}-\mathrm{HOAc}=30: 1: 1 \rightarrow 1: 1: 1\right)$ and the resultant active fractions were applied on the HPLC (Apollo $\mathrm{C}_{18}$, $10 \times 250 \mathrm{~mm}$, Alltech, $1 \% \mathrm{HOAc}$ in 33 and $38 \% \mathrm{MeOH}$ of Fr. 10-3 and Fr. 10-5, respectively) to give compound 1 (4.0 $\mathrm{mg}) .{ }^{1} \mathrm{H}$ - and ${ }^{13} \mathrm{C}$-NMR spectra were recorded on a Bruker Avance Digital 400 spectrometer (Karlsruhe, Germany) at 400 and $100 \mathrm{MHz}$, respectively. Chemical shifts are given in $\delta$ (ppm) from TMS (tetramethylsilane). Silica gel column chromatography was carried out using a Kiesel gel 60 (Merck, U.S.A.).

Compound 1: Oxyresveratrol: ${ }^{1} \mathrm{H}-\mathrm{NMR} \quad(400 \mathrm{MHz}$, $\left.\mathrm{CD}_{3} \mathrm{OD}\right) \delta=6.12\left(2 \mathrm{H}, \mathrm{t}, J=2.1 \mathrm{~Hz}, \mathrm{H}-4^{\prime}\right), 6.30(1 \mathrm{H}, \mathrm{d}$, $J=2.5 \mathrm{~Hz}, \mathrm{H}-3), 6.30(1 \mathrm{H}, \mathrm{dd}, J=7.7,2.5 \mathrm{~Hz}, \mathrm{H}-5), 6.43(2 \mathrm{H}$, d, $\left.J=2.1 \mathrm{~Hz}, \mathrm{H}-2^{\prime}, 6^{\prime}\right), 6.80\left(1 \mathrm{H}, \mathrm{d}, J=16.4 \mathrm{~Hz}, \mathrm{H}-7^{\prime}\right), 7.26$ $(1 \mathrm{H}, \mathrm{d}, J=16.4 \mathrm{~Hz}, \mathrm{H}-7), 7.32(1 \mathrm{H}, \mathrm{d}, J=8.7 \mathrm{~Hz}, \mathrm{H}-6) .{ }^{13} \mathrm{C}-$ NMR $\left(100 \mathrm{MHz}, \mathrm{CD}_{3} \mathrm{OD}\right) \quad \delta=102.3\left(\mathrm{C}-4^{\prime}\right), 103.5(\mathrm{C}-3)$, 105.6 (C-2', 6'), 108.3 (C-5), 117.8 (C-1), 124.8 (C-7), 126.4 (C-7'), 128.4 (C-6), 142.1 (C-1'), 157.2 (C-2), 159.2 (C-4), 159.6 $\left(\mathrm{C}-3^{\prime}\right) .{ }^{24)}$ The structure of oxyresveratrol is presented in Fig. 1.

Chemicals (Reagents), Physiological Solution and Treatment $\mathrm{A} \beta(25-35)$ was purchased from Bachem (Bubendorf, Switzerland). 2-Mercaptoethanol, 3-[4,5-dimethylthiazol-2-yl]-2,5-diphenyl-tetrazolium bromide (MTT), o-phthaldialdehyde (OPA), trypsin (from bovine pancreas), Dulbecco's modified Eagle's medium (DMEM), Joklik-modified MEM, poly-L-lysine and amino acids for HPLC standard were purchased from Sigma Chemical Co. (St. Louis, MO, U.S.A.). Hoechst 33342 dye, fluo-4 AM and 2', 7'-dichlorodihydrofluorescin diacetate $\left(\mathrm{H}_{2} \mathrm{DCF}-\mathrm{DA}\right)$ were purchased from Molecular Probes Inc. (Eugene, OR, U.S.A.). Fetal bovine serum was purchased from JRH Biosciences (Lenexa, KS, U.S.A.). All other chemicals used were of the highest grade available.

A $\beta$ (25-35) stock solution of $2 \mathrm{~mm}$ was prepared in sterile distilled water, stored at $-20^{\circ} \mathrm{C}$, and incubated for more than $2 \mathrm{~d}$ at $37^{\circ} \mathrm{C}$ to aggregate before use. Oxyresveratrol was dissolved in dimethylsulfoxide (DMSO) with the concentration of $20 \mathrm{~mm}$ and further diluted with experimental buffers. The final concentration of DMSO was $0.05 \%$, which did not affect cell viability (data not shown). For every experiment, oxyresveratrol and the vehicle were applied $15 \mathrm{~min}$ prior to the treatment with $10 \mu \mathrm{M} \mathrm{A} \beta(25-35)$ and were present in the medium during the incubation period with $\mathrm{A} \beta(25-35)$. For some experiments, a HEPES-buffered solution (incubation buffer) containing $8.6 \mathrm{~mm}$ HEPES, $154 \mathrm{~mm} \mathrm{NaCl}$, $5.6 \mathrm{~mm} \mathrm{KCl}$ and $2.3 \mathrm{~mm} \mathrm{CaCl}_{2}$ at $\mathrm{pH} 7.4$ was used.
Experimental Animals Specific pathogen-free pregnant Sprague-Dawley (SD) rats (Daehan Biolink Co. Ltd., Chungbuk, Korea) were housed singly in an environmentally controlled room with temperature of $23 \pm 2{ }^{\circ} \mathrm{C}$, relative humidity of $55 \pm 5 \%$, and a 12 -h light/dark cycle. Food and tap water for rats were available ad libitum. The procedures involving experimental animal comply with the regulations of the animal ethnical committee of Chungbuk National University for the care and use of laboratory animals.

Primary Culture of Cerebral Cortical Neurons Primary cortical neuronal cultures were prepared using SD rat fetuses on embryonic days 15 to 16 , as described previously. ${ }^{25)}$ Briefly, fetuses were isolated from a dam anaesthetized with ether. Cortical hemispheres were dissected under sterile conditions and placed into Joklik-modified Eagle's medium containing trypsin $(0.25 \mathrm{mg} / \mathrm{ml})$. After triturating five to six times through a $5-\mathrm{ml}$ pipette, the cells were incubated for $10 \mathrm{~min}$ at $37^{\circ} \mathrm{C}$. Dissociated cells were collected by centrifugation $(1500 \mathrm{rpm}, 5 \mathrm{~min})$ and resuspended in DMEM supplemented with sodium pyruvate $(0.9 \mathrm{mM})$, Lglutamine $(3.64 \mathrm{~mm})$, sodium bicarbonate $(44 \mathrm{~mm})$, glucose (22.73 mM), penicillin $(40 \mathrm{U} / \mathrm{ml})$, gentamicin $(50 \mu \mathrm{g} / \mathrm{ml}), \mathrm{KCl}$ $(5 \mathrm{~mm})$ and $10 \%$ fetal bovine serum at a density of about $2 \times 10^{6}$ cells $/ \mathrm{ml}$. Cells were plated onto poly-L-lysine coated 12 well-plates (Corning 3512, NY, U.S.A.) for the measurements of cell death and glutamate release, and coverslips (Fisher Scientific 12CIR, Pittsburgh, PA, U.S.A.) for the measurements of cytosolic $\mathrm{Ca}^{2+}$ concentration $\left(\left[\mathrm{Ca}^{2+}\right]_{c}\right)$, reactive oxygen species (ROS) and apoptosis. After 2 days' incubation, the medium was replaced with a new growth medium in which the concentrations of fetal bovine serum and $\mathrm{KCl}$ were changed to $5 \%$ and $15 \mathrm{~mm}$, respectively. Cultures were kept at $37^{\circ} \mathrm{C}$ in a $5 \% \mathrm{CO}_{2}$ atmosphere, changing the medium twice a week. Neurotoxicity experiments were performed on neurons grown for 5-7 d in vitro. Immunochemical staining with anti-microtubule associated protein-2 (MAP-2) antibody and anti-glial fibrillary acidic protein (GFAP) antibody revealed that the culture method used in this study provided cell cultures containing about $90 \%$ neurons.

MTT Cell Viability Assay This method is based on the reduction of the tetrazolium salt MTT into a crystalline blue formazan product by the cellular oxidoreductase. ${ }^{26)}$ Therefore, the amount of formazan produced is proportional to the number of viable cells. The culture medium was removed and replaced with serum-free growth medium. Cells were then incubated for $20 \mathrm{~min}$ in the medium, and incubated for a further $24 \mathrm{~h}$ in the presence of $10 \mu \mathrm{M} \mathrm{A} \beta(25-35)$ at $37^{\circ} \mathrm{C}$ to produce neurotoxicity. After completing the incubation with $10 \mu \mathrm{m} \mathrm{A} \beta$ (25-35), the culture medium was replaced by a solution of MTT $(0.5 \mathrm{mg} / \mathrm{ml})$ in serum-free growth medium. After a $4 \mathrm{~h}$ incubation at $37^{\circ} \mathrm{C}$, this solution was removed, and the resulting blue formazan was solubilized in $0.4 \mathrm{ml}$ of acid-isopropanol $(0.04 \mathrm{~N} \mathrm{HCl}$ in isopropanol), and the optical density was read at $570 \mathrm{~nm}$ using microplate reader (Bio-Tek ELX808, VT, U.S.A.). Serum-free growth medium was used as blank solution.

Measurement of Apoptotic Neuronal Death The bisbenzimidazole dye, Hoechst 33342, penetrates the plasma membrane and stains DNA in cells without permeabilization. ${ }^{27)}$ In contrast to normal cells, the nuclei of apoptotic 
cells have highly condensed chromatin that is uniformly stained by Hoechst 33342. These morphological changes in the nuclei of apoptotic cells may be visualized by fluorescence microscopy. Exposed to $10 \mu \mathrm{M} \mathrm{A} \beta(25-35)$ in serumfree growth medium for $24 \mathrm{~h}$ as described in MTT assay, neurons on coverslips were fixed in $4 \%$ paraformaldehyde at the room temperature for $20 \mathrm{~min}$, and then stained with Hoechst 33342 dye at the concentration of $1 \mu \mathrm{g} / \mathrm{ml}$ in the incubation buffer for $15 \mathrm{~min}$. The morphological change was examined under UV illumination using a fluorescence microscope (Olympus IX70-FL, Tokyo, Japan). The dye was excited at $340 \mathrm{~nm}$, and emission was filtered with a $510 \mathrm{~nm}$ barrier filter. To quantify the apoptotic process, neurons with fragmented or condensed DNA and normal DNA were counted. Data was shown as apoptotic neurons as a percentage of total neurons.

Measurement of $\left[\mathrm{Ca}^{2+}\right]_{\mathbf{c}}$ Neurons grown on coverslips were loaded with $3 \mu \mathrm{M}$ fluo-4 AM (dissolved in DMSO) in serum-free growth medium for $45 \mathrm{~min}$ at $37^{\circ} \mathrm{C}$ in the $\mathrm{CO}_{2}$ incubator, and washed with the incubation buffer. The coverslips containing fluo-4 AM labeled neurons were mounted on a perfusion chamber containing incubation buffer, subjected to a laser scanning confocal microscope (Carl Zeiss LSM 510 , Oberkochen, Germany), and then scanned every $5 \mathrm{~s}$ with a $488 \mathrm{~nm}$ excitation argon laser and a $515 \mathrm{~nm}$ longpass emission filter. After the baseline of $\left[\mathrm{Ca}^{2+}\right]_{c}$ was observed for $30 \mathrm{~s}, 10 \mu \mathrm{M} \mathrm{A} \beta(25-35)$ was added to the perfusion chamber for the measurement of $\left[\mathrm{Ca}^{2+}\right]_{\mathrm{c}}$ change. In order to test the effect of oxyresveratrol on $\mathrm{A} \beta(25-35)$-induced $\left[\mathrm{Ca}^{2+}\right]_{\mathrm{c}}$ change, neurons were pretreated with the compound $15 \mathrm{~min}$ before the treatment with $\mathrm{A} \beta(25-35)$ after being loaded with fluo-4 AM and washed. The compound was also present in the perfusion chamber during the $\left[\mathrm{Ca}^{2+}\right]_{c}$ measurement period. All images, about 100 images from the scanning, were processed to analyze changes of $\left[\mathrm{Ca}^{2+}\right]_{\mathrm{c}}$ in a single cell level. The results were expressed as the relative fluorescence intensity (RFI). ${ }^{28)}$

Measurement of Glutamate Concentration After being washed and equilibrated for $20 \mathrm{~min}$ with the incubation buffer, neurons were incubated with the buffer containing $10 \mu \mathrm{M} \mathrm{A} \beta(25-35)$ for $6 \mathrm{~h}$ at $37^{\circ} \mathrm{C}$. At the end of the incubation, glutamate secreted into the medium from the treated cells was quantified by high performance liquid chromatography (HPLC) with an electrochemical detector (ECD) (BAS MF series, IN, U.S.A.). ${ }^{25)}$ Briefly, after a small aliquot was collected from the culture wells, glutamate was separated on an analytical column (ODS2; particle size, $5 \mu \mathrm{m} ; 4.6 \times 100$ $\mathrm{mm}$ ) after pre-derivatization with OPA/2-mercaptoethanol. Derivatives were detected by electrochemistry at $0.1 \mu \mathrm{A} / \mathrm{V}$, and the reference electrode was set at $0.7 \mathrm{~V}$. The column was eluted with mobile phase ( $\mathrm{pH} 5.20$ ) containing $0.1 \mathrm{M}$ sodium phosphate buffer with $37 \%(\mathrm{v} / \mathrm{v})$ HPLC-grade methanol at a flow rate of $0.5 \mathrm{ml} / \mathrm{min}$.

Measurement of ROS Generation The microfluorescence assay of $2^{\prime}, 7^{\prime}$-dichlorofluorescin (DCF), the fluorescent product of $\mathrm{H}_{2} \mathrm{DCF}-\mathrm{DA}$, was used to monitor the generation of ROS. Neurons grown on coverslips were washed with phenol red-free DMEM 3 times and incubated with the buffer containing $10 \mu \mathrm{M} \mathrm{A} \beta(25-35)$ at $37^{\circ} \mathrm{C}$ for $24 \mathrm{~h}$. The uptake of $\mathrm{H}_{2} \mathrm{DCF}-\mathrm{DA}$ (final concentration, $5 \mu \mathrm{M}$ ) dissolved in DMSO was carried out for the last $10 \mathrm{~min}$ of the incubation with $10 \mu \mathrm{M} \mathrm{A} \beta$ (25-35). After being washed, coverslips containing cortical neurons loaded with $\mathrm{H}_{2} \mathrm{DCF}-\mathrm{DA}$ were mounted on the confocal microscope stage, and the neurons were observed by a laser scanning confocal microscope (BioRad, MRC1024ES, Maylands, U.K.) using $488 \mathrm{~nm}$ excitation and $510 \mathrm{~nm}$ emission filters. The average pixel intensity of fluorescence was measured within each cell in the field and expressed in the relative units of DCF fluorescence. Values for the average staining intensity per cell were obtained using the image analyzing software supplied by the manufacturer. Challenge of $\mathrm{H}_{2} \mathrm{DCF}-\mathrm{DA}$ and measurement of fluorescence intensity was performed in the dark.

Statistical Analysis Data were expressed as mean士 S.E.M. and statistical significance was assessed by one-way analysis of variance (ANOVA) with subsequent Turkey's tests. $p$ values of $<0.05$ were considered to be significant.

\section{RESULTS}

Oxyresveratrol Protects Neurons against Cell Death Induced by $\mathbf{A} \boldsymbol{\beta}$ (25-35) To assess $\mathrm{A} \beta$ (25-35)-induced neuronal cell death, the MTT assay was performed. In previous experiments, ${ }^{25,26)}$ we have demonstrated that $\mathrm{A} \beta(25-$ 35 ) over the concentration range of $5-20 \mu \mathrm{M}$ produced a concentration-dependent reduction of cell viability in cultured cortical neurons. Therefore, the concentration of $10 \mu \mathrm{M}$ was used for the determination of $\mathrm{A} \beta$ (25-35)-induced neuronal cell damage in the present experiments. Furthermore, the toxicity of $10 \mu \mathrm{M} \mathrm{A} \beta(25-35)$ was very similar to that of $5 \mu \mathrm{M} \mathrm{A} \beta(1-42)$ on cultured cortical neurons. Figure 2 shows the inhibitory effect of oxyresveratrol on a $10 \mu \mathrm{m} \mathrm{A} \beta$ (25-35)-induced decrease of MTT reduction. MTT reduction rate decreased to $66.5 \pm 2.5 \%$ when using $10 \mu \mathrm{M} \mathrm{A} \beta$ $(25-35)$. Oxyresveratrol concentration-dependently reduced the A $\beta(25-35)$-induced decrease of MTT reduction over a concentration range of $1-10 \mu \mathrm{M}$ showing $91.3 \pm 2.1 \%$ with $10 \mu \mathrm{M}$ as a maximal effect.

An additional experiment was performed with Hoechst 33342 staining to assess the neurotoxicity of $\mathrm{A} \beta(25-35)$. Cell nuclei stained by Hoechst 33342 enables the occurrence of DNA condensate to be detected, a feature of apoptosis. In neurons treated with $10 \mu \mathrm{M} \mathrm{A} \beta(25-35)$, chromatin conden-

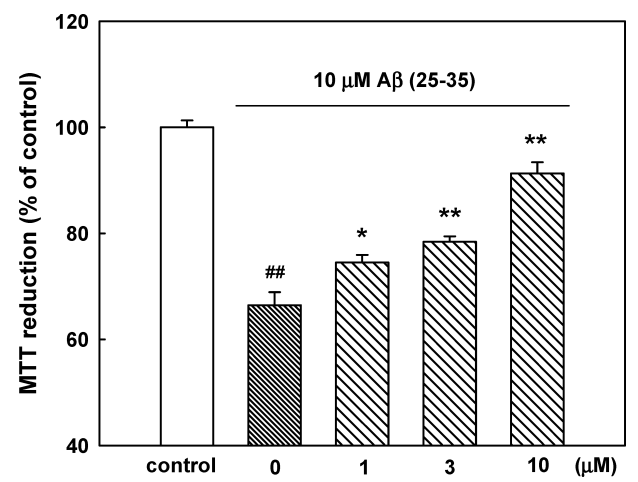

Fig. 2. Inhibitory Effect of Oxyresveratrol on $\mathrm{A} \beta$ (25-35)-Induced Cell Death in Cultured Cortical Neurons

Neuronal death was measured by the MTT assy. The absorbance of non-treated cells was regarded as $100 \%$. Results are expressed as mean \pm S.E.M. values of the data obtained from four independent experiments performed in two to four wells. \# $p<0.01$ compared to control. $* p<0.05, * * p<0.01$ compared to $10 \mu \mathrm{M} \mathrm{A} \beta(25-35)$. 


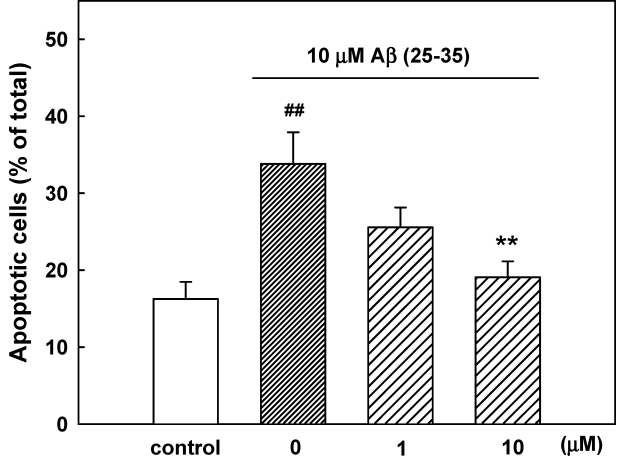

Fig. 3. Inhibitory Effect of Oxyresveratrol on A $\beta$ (25-35)-Induced Apoptosis of Cultured Cortical Neurons as Measured by Hoechst 33342 Staining

Apoptotic cells were counted from 5 to 6 fields per well. Results are shown as apop totic cells as a percentage of total number of cells and expressed as mean \pm S.E.M. values of the data obtained from four independent experiments performed in three or four wells. $p<0.01$ compared to control. **p $<0.01$ compared to $10 \mu \mathrm{M} \mathrm{A} \beta(25-35)$.

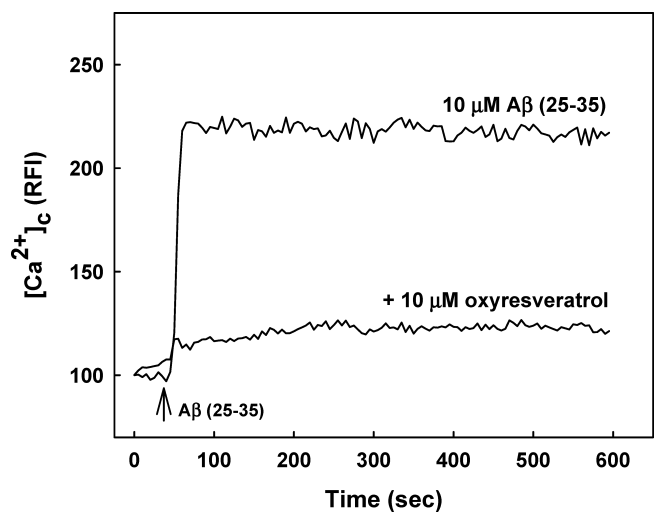

Fig. 4. Change of $\left[\mathrm{Ca}^{2+}\right]_{\mathrm{c}}$ in Response to $\mathrm{A} \beta(25-35)$ in the Presence or Absence of Oxyresveratrol in Cultured Cortical Neurons.

$\left[\mathrm{Ca}^{2+}\right]_{\mathrm{c}}$ was monitored using a laser scanning confocal microscope. All images from the scanning were processed to analyze changes of $\left[\mathrm{Ca}^{2+}\right]_{\mathrm{c}}$ in a single cell level. Results are expressed as the relative fluorescence intensity (RFI). Each trace is a single cell representative from at least three independent experiments.

sation and nuclear fragmentation were observed, whereas the control culture had round blue nuclei of viable neurons. The proportion of apoptotic neurons was calculated in Fig. 3. The treatment of neurons with $10 \mu \mathrm{M} \mathrm{A} \beta(25-35)$ produced apoptosis of $33.8 \pm 4.1 \%$ of the total population of cultured cortical neurons, as compared with $16.2 \pm 2.2 \%$ of apoptotic neurons in control cultures. On the other hand, the addition of oxyresveratrol significantly decreased the $\mathrm{A} \beta(25-35)$-induced apoptotic cell death, showing $19.1 \pm 2.1 \%$ at the concentration of $10 \mu \mathrm{M}$. Oxyresveratrol did not affect cell viability (data not shown).

Oxyresveratrol Inhibits $\mathbf{A} \boldsymbol{\beta}(\mathbf{2 5}-35)$-Induced Elevation of $\left[\mathrm{Ca}^{2+}\right]_{c}$ The increase of $\left[\mathrm{Ca}^{2+}\right]_{\mathrm{c}}$ has been postulated to be associated with $\mathrm{A} \beta$-induced cell death in many studies. As shown in Fig. 4, $\left[\mathrm{Ca}^{2+}\right]_{c}$ rapidly increased with the treatment of $10 \mu \mathrm{M} \mathrm{A} \beta(25-35)$, and maintained plateau throughout the recording period showing a maximal fluorescence intensity of about 220 compared to a base of 100 . In contrast, pretreatment with oxyresveratrol $(10 \mu \mathrm{M})$ completely inhibited the elevation of $\left[\mathrm{Ca}^{2+}\right]_{c}$ induced by $10 \mu \mathrm{M}$ A $\beta(25-35)$ throughout the measurement period. Oxyresveratrol did not affect basal $\left[\mathrm{Ca}^{2+}\right]_{\mathrm{c}}$ (data not shown).

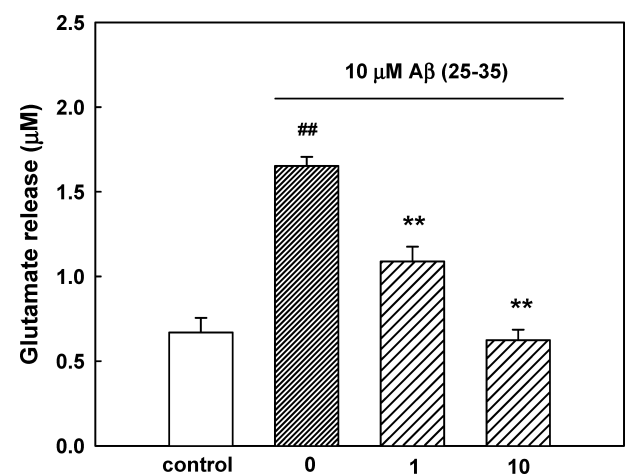

Fig. 5. Inhibitory Effect of Oxyresveratrol on A $\beta$ (25-35)-Induced Glutamate Release in Cultured Cortical Neurons

The amount of released glutamate was measured by HPLC with ECD. Results are expressed as mean \pm S.E.M. values of the data obtained from three independent experiments performed in two or three wells. $p<0.01$ compared to control. $* * p<0.01 \mathrm{com}-$ pared to $10 \mu_{\mathrm{M} \mathrm{A}} \beta(25-35)$.

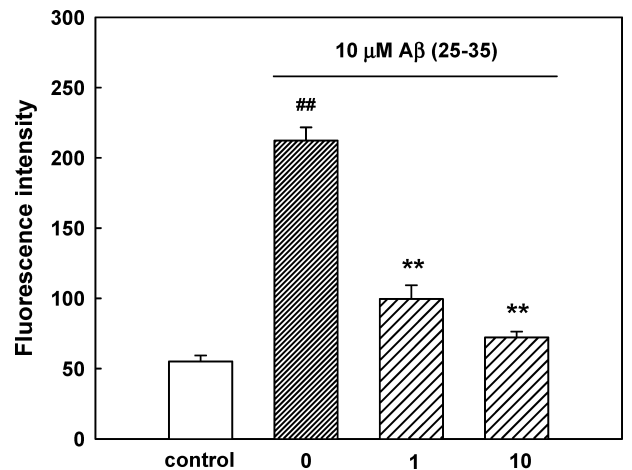

Fig. 6. Inhibitory Effect of Oxyresveratrol on A $\beta$ (25-35)-Induced ROS Generation in Cultured Cortical Neurons

Values represent mean \pm S.E.M. of relative fluorescence intensity obtained from foru independent experiments performed in three or four wells. \# $p<0.01$ compared to control. $* * p<0.01$ compared to $10 \mu \mathrm{m} \mathrm{A} \beta(25-35)$.

Oxyresveratrol Inhibits $\mathbf{A} \boldsymbol{\beta}$ (25-35)-Induced Elevation of Glutamate Release Glutamate released into the extracellular medium by the treatment with $10 \mu \mathrm{M} \mathrm{A} \beta(25-35)$ for $6 \mathrm{~h}$ was quantified. As shown in Fig. 5, $10 \mu \mathrm{M} \mathrm{A} \beta$ (25$35)$ markedly elevated the basal glutamate level from 0.43 $\pm 0.08 \mu \mathrm{M}$ of control neurons to $1.16 \pm 0.10 \mu \mathrm{M}$. Oxyresveratrol concentration-dependently blocked the $\mathrm{A} \beta(25-35)$-induced elevation of glutamate release showing $0.62 \pm 0.06 \mu \mathrm{M}$ at the concentration of $10 \mu \mathrm{M}$.

Oxyresveratrol Inhibits A $\boldsymbol{\beta}$ (25-35)-Induced ROS generation $\mathrm{A} \beta(25-35)$ increased the glutamate release and the concentration of $\left[\mathrm{Ca}^{2+}\right]_{\mathrm{c}}$. Furthermore, the pathological condition induced by $\mathrm{A} \beta(25-35)$ is associated with accelerated formation of ROS. In $\mathrm{A} \beta(25-35)(10 \mu \mathrm{M})$-treated cells for $24 \mathrm{~h}$, the fluorescence intensity increased about 4

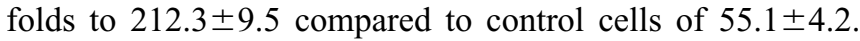
The $\mathrm{A} \beta(25-35)$-induced increase of ROS generation was significantly inhibited by oxyresveratrol (Fig. 6). Oxyresveratrol did not show direct reaction with $\mathrm{H}_{2} \mathrm{DCF}-\mathrm{DA}$ to generate fluorescence (data not shown).

\section{DISCUSSION}

The present study provides evidence that $\mathrm{A} \beta(25-35)$-in- 
duced injury to rat cortical neurons can be prevented by oxyresveratrol derived from Smilacis Chinae rhizome. Oxyresveratrol was able to reduce the $\mathrm{A} \beta(25-35)$-induced $\left[\mathrm{Ca}^{2+}\right]_{\mathrm{c}}$ increase, glutamate release and ROS generation, and, in result, attenuate apoptotic neuronal death in primarily cultured rat cortical neurons.

$\mathrm{A} \beta$-induced neurotoxicity has been attributed in various studies to $\mathrm{Ca}^{2+}$ influx and generation of ROS. ${ }^{29-31)}$ Our previous studies confirmed that $\mathrm{A} \beta(25-35)$ caused elevation of $\left[\mathrm{Ca}^{2+}\right]_{\mathrm{c}}$, glutamate release, ROS generation and then apoptotic neuronal cell death. These neuronal cell damage induced by $\mathrm{A} \beta(25-35)$ was blocked by the treatment with $(5 R, 10 S)-(+)-5$-methyl-10,11-dihydro-5H-dibenzo[a,d]cyclohepten-5,10-imine (MK-801), an NMDA receptor antagonist, verapamil, an L-type $\mathrm{Ca}^{2+}$ channel blocker, and $\mathrm{N}^{\mathrm{G}}$ nitro-L-arginine methyl ester (L-NAME), a nitric oxide synthase (NOS) inhibitor. ${ }^{23,25,26)}$ These results imply the involvement of NMDA-glutamate receptor activation, an increase of $\mathrm{Ca}^{2+}$ influx and generation of ROS in $\mathrm{A} \beta(25-35)$-induced neurotoxicity in cultured cortical neurons, as evidenced in other studies. ${ }^{8-10)}$ Regardless of the relative contribution of these events to $\mathrm{A} \beta(25-35)$-induced neurotoxicity, the primary event following $\mathrm{A} \beta(25-35)$ treatment of cultured neurons has been suggested to be $\mathrm{Ca}^{2+}$ influx, apparently via $\mathrm{L}$-type voltage-dependent $\mathrm{Ca}^{2+}$ channel (L-VDCC), since blockage of this channel and/or $\mathrm{Ca}^{2+}$ chelation prevents all other consequences. ${ }^{9,32)}$ Furthermore, $\mathrm{A} \beta$ (25-35)-induced elevation of $\left[\mathrm{Ca}^{2+}\right]_{c}$ and neurotoxicity were inhibited by MK-801, suggesting $\mathrm{Ca}^{2+}$ influx through NMDA receptorcoupled L-VDCC plays a critical role in the neurotoxicity. $^{23,25,26,33)}$ In the present study, $\mathrm{A} \beta(25-35)$ elicited a rapid and significant $\left[\mathrm{Ca}^{2+}\right]_{\mathrm{c}}$ increase, which was blocked by oxyresveratrol. It is presumed that oxyresveratrol may cause membrane stabilization, resulting in blockade of $\mathrm{Ca}^{2+}$ influx via L-VDCC. Oxyresveratrol also significantly inhibited the A $\beta$ (25-35)-induced glutamate elevation. These results indicate that the sustained inhibition on $\left[\mathrm{Ca}^{2+}\right]_{\mathrm{c}}$ elevation by oxyresveratrol resulted in the decrease of the $\mathrm{A} \beta(25-35)$ induced glutamate release.

ROS generation undoubtedly takes place in glutamate neurotoxicity and is likely due to $\mathrm{Ca}^{2+}$ influx in the cytosol. ${ }^{34)}$ Many reports demonstrated the involvement of ROS formation in $\mathrm{A} \beta$-induced neurotoxicity. ${ }^{29,35)}$ Oxyresveratrol decreased the $\mathrm{A} \beta$ (25-35)-induced increase of ROS generation in the present study. It has been reported that vitamin-E, an antioxidant, blocked the $\mathrm{A} \beta$-induced generation of ROS, but not $\mathrm{Ca}^{2+}$ influx, and reduction of extracellular $\mathrm{Ca}^{2+}$ inhibited the $\mathrm{A} \beta$-induced increase in intracellular $\mathrm{Ca}^{2+}$ as well as generation of ROS, indicating that ROS generation is a consequence of $\mathrm{Ca}^{2+}$ accumulation. ${ }^{10)}$ It was demonstrated that the significant increase of ROS generation took more than $1 \mathrm{~h}$, while the elevation of $\left[\mathrm{Ca}^{2+}\right]_{\mathrm{c}}$ occurred within seconds after the treatment with $10 \mu \mathrm{M} \mathrm{A} \beta(25-35) .{ }^{25)}$ In addition, L-NAME, a NOS inhibitor, failed to inhibit the $\mathrm{A} \beta$ $(25-35)$-induced increase in $\left[\mathrm{Ca}^{2+}\right]_{c}$ in the short period of measurement in contrast to the complete inhibition of verapamil on the $\mathrm{A} \beta$ (25-35)-induced ROS generation in the previous data. ${ }^{23,25,26)}$ Therefore, it is concluded that oxyresveratrol inhibited the A $\beta$ (25-35)-induced ROS generation via the blockade of $\left[\mathrm{Ca}^{2+}\right]_{\mathrm{c}}$ increase. Resveratrol has been demonstrated to have protective effect against $\mathrm{A} \beta$-in- duced neuronal death in cultures. ${ }^{16-19)}$ The neuroprotective effect of resveratrol, however, has been concluded to be attributable to its inhibitory effect on ROS generation. Here, we conclude that the inhibition of $\left[\mathrm{Ca}^{2+}\right]_{\mathrm{c}}$ elevation by oxyresveratrol is primarily responsible for its prevention of A $\beta$ (25-35)-induced neuronal cell damage. It is unclear how oxyresveratrol blocks $\left[\mathrm{Ca}^{2+}\right]_{\mathrm{c}}$ elevation. It should be further studied.

Many researchers have demonstrated that $\mathrm{A} \beta$ triggered apoptotic degeneration in in vitro neuronal experiment. ${ }^{33,36}$ Cultured cortical neurons exposed to $10 \mu \mathrm{M} \mathrm{A} \beta(25-35)$ for more than $24 \mathrm{~h}$ showed increased chromatin condensation, a typical feature of apoptotic cell death, in the present work. Oxyresveratrol protected the neuronal cell against $\mathrm{A} \beta(25-$ 35 )-induced apoptotic death in the present work. It is thus concluded that oxyresveratrol may prevent the $\mathrm{A} \beta(25-35)$ induced apoptosis of neuronal cell by interfering with the increase of $\left[\mathrm{Ca}^{2+}\right]_{c}$, and then by inhibiting glutamate release and ROS generation in cortical neurons.

$\mathrm{A} \beta$ is believed to play a central role in the pathophysiology of $\mathrm{AD} .^{37,38)}$ Although it is still controversial whether increased $\mathrm{A} \beta$ formation is sufficient to cause nerve cell degeneration in $\mathrm{AD}$, neurotoxic effects of $\mathrm{A} \beta$ have been demonstrated in both in vitro and in vivo. ${ }^{2,3}$ Oxyresveratrol markedly blocked $\mathrm{A} \beta$ (25-35)-induced neuronal cell death in the present study. We isolated oxyresveratrol from the methanolic extract of Smilacis chinae rhizome which was proved to have remarkable inhibition on $\mathrm{A} \beta$ (25-35)induced neuronal damage in cultured cortical neurons. ${ }^{23)}$ These results suggest a further evidence of the possibility of Smilacis chinae rhizome having neuroprotective effect in AD brains with the prevention of the disease progression. In conclusion, oxyresveratrol could be responsible for the neuroprotective effect of Smilacis chinae rhizome. Furthermore we demonstrated a novel pharmacological action of oxyresveratrol and its mechanism. As far as we know, this is the first report to demonstrate the neuroprotective effect of oxyresveratrol against $\mathrm{A} \beta$-induced toxicity in cultured neurons. The protection against $\mathrm{A} \beta$ (25-35)-induced neurotoxicity by oxyresveratrol may help to explain at least its inhibitory action on the progression of $\mathrm{AD}$, and provide the pharmacological basis of their clinical usage in treatment of neurodegeneration in $\mathrm{AD}$.

Acknowledgements This work was supported by a grant from BioGreen 21 Program, Rural Development Administration, Republic of Korea and the Brain Korea 21 Project in 2006.

\section{REFERENCES}

1) Ivins K. J., Ivins J. K., Sharp J. P., Cotman C W., J. Biol. Chem., 274, 2107-2112 (1999).

2) Iversen L. L., Mortishier-Smith R. J., Pollack S. J., Shearman M. S., Biochem. J., 311, 1-16 (1995).

3) Chen S. Y., Harding J. W., Barnes C. D., Brain Res., 715, 44-50 (1996).

4) Ueda K., Fukui Y., Kageyama H., Brain Res., 639, 240-244 (1994).

5) Koh J. Y., Yang L. L., Cotman C. W., Brain Res., 533, 315-320 (1990).

6) Goodman Y., Mattson M. P., Exp. Neurol., 128, 1-12 (1994).

7) Forloni G., Funct. Neurol., 8, 211-225 (1993).

8) Gray C. W., Patel A. J., Brain Res., 691, 169-179 (1995). 
9) Ueda K., Shinohara S., Yagami T., Asakura K., Kawasaki K., J. Neurochem., 68, 265-271 (1997).

10) Ekinci F. J., Linsley M. D., Shea T. B., Mol. Brain Res., 76, 389-395 (2000).

11) Fremont L., Life Sci., 66, 663-673 (2000).

12) Hung L. M., Chen J. K., Lee R. S., Liang H. C., Su M. J., Free Radic. Biol. Med., 30, 877-883 (2001).

13) Stojanovic S., Sprinz H., Brede O., Arch. Biochem. Biophys., 391, $79-89$ (2003).

14) Huang S. S., Tsai M. C., Chih C. L., Hung L. M., Tsai S. K., Life Sci., 69, 1057-1065 (2001).

15) Wang Q., Xu J., Rottinghaus G. E., Simonyi A., Lubahn D., Sun G. Y., Sun A. Y., Brain Res., 958, 439-447 (2002).

16) Conte A., Pellegrini S., Tagliazucchi D., Drugs Exp. Clin. Res., 29, $243-255$ (2003).

17) Han Y. S., Zheng W. H., Bastianetto S., Chabot J. G., Quirion R., Br. J. Pharmacol., 141, 997-1005 (2004).

18) Savaskan E., Olivieri G., Meier F., Seifritz E., Wirz-Justice A., MullerSpahn F., Gerontology, 49, 380-383 (2003).

19) Marambaud P., Zhao H., Davies P., J. Biol. Chem., 280, 37377-37382 (2005).

20) Lorenz P., Roychowdhury S., Engelmann M., Wolf G., Horn T. F., Nitric Oxide, 9, 64-76 (2003).

21) Andrabi S. A., Spina M. G., Lorenz P., Ebmeyer U., Wolf G., Horn T. F., Brain Res., 1017, 98-107 (2004).

22) Breuer C., Wolf G., Andrabi S. A., Lorenz P., Horn T. F., Neurosci. Lett. 393, 113-118 (2006).

23) Ban J. Y., Cho S. O., Koh S. B., Song K. S., Bae K. W., Seong Y. H., J. Ethnopharmacol., 106, 230-237 (2006).

24) Kanchanapoom T., Suga K., Kasai R., Yamasaki K., Kamel M. S., Mo- hamed M. H., Chem. Pharm. Bull., 50, 863-865 (2002).

25) Ban J. Y., Seong Y. H., Eur. J. Pharmacol., 520, 12-21 (2005).

26) Lee B. Y., Ban J. Y., Seong Y. H., Neurosci. Res., 52, 347-356 (2005).

27) Ishikawa Y., Satoh T., Enokido Y., Nishio C., Ikeuchi T., Hatanaka H., Brain Res., 824, 71-80 (1999).

28) Lee Z. W., Kweon S. M., Kim B. C., Leem S. H., Shin I., Kim J. H., Ha K. S., J. Biol. Chem., 273, 12710-12715 (1998).

29) Miranda S., Opazo C., Larrondo L. F., Munoz F. J., Ruiz F., Leighton F., Inestrosa N. C., Prog. Neurobiol., 62, 633-648 (2000).

30) Behl C., Davis J. B., Lesley R., Schubert D., Cell, 77, 817-827 (1994).

31) Arias C., Arrieta I., Tapia R., J. Neurosci. Res., 41, 561-566 (1995).

32) Ekinci F. J., Malik K. U., Shea T. B., J. Biol. Chem., 274, 3032230327 (1999).

33) Harkany T., Hortobagyi T., Sasvari M., Konya C., Penke B., Luiten P. G., Nyakas C., Prog. Neuropsychopharmacol. Biol. Psychiatry., 23, 963-1008 (1999).

34) Pereira C. F., Oliveira C. R., Neurosci. Res., 37, 227-236 (2000).

35) Morais Cardoso S., Swerdlow R. H., Oliveira C. R., Brain Res., 931, $117-125$ (2002)

36) Yan X. Z., Qiao J. T., Dou Y., Qiao Z. D., Neuroscience, 92, 177-184 (1999).

37) Hsiao K. K., Borchelt D. R., Olson K., Johannsdottir R., Kitt C., Yunis W., Xu S., Eckman C., Younkin S., Price D., Iadecola C., Clark H. B., Carlson G., Neuron, 15, 1203-1218 (1995).

38) Holcomb L., Gordon M. N., McGowan E., Yu X., Benkovic S., Kantzen P., Wright K., Saad I., Mueller R., Morgan D., Sanders S., Nat. Med., 4, 97-100 (1998). 